\title{
SUPPORTING FIGURES
}

Figure S1. Non-ionic detergent improves SRL cleavage kinetics at low restrictocin concentration. (A) Cleavage of SRL RNA by restrictocin occurs with non-exponential kinetics and fails to produce similar curves in repeated experiemnts. Addition of bovine serum albumin (BSA) does not prevent non-exponential kinetics and rate variability. (B) Addition of Triton-X100 results in exponential kinetics (not shown) and allows reproducible SRL cleavage kinetics at low restrictocin concentrations as indicated by the smaller error bars for two independent measurements at $0.02,0.1$ and $1 \%$ Triton-X-100 compared to detergent-free reaction. Reactions were done at $37^{\circ} \mathrm{C}$ and contained $10 \mathrm{mM}$ Tris $\cdot \mathrm{HCl} \mathrm{pH} 7.4,<1 \mathrm{nM}{ }^{32} \mathrm{P}-\mathrm{SRL}, 1 \mathrm{nM}$ restrictocin, $37^{\circ} \mathrm{C}$ and T-X-100.

Figure S2. Impurities from PAGE inhibit restrictocin-catalyzed SRL cleavage. (A) Dilution of PAGE-purified ${ }^{32} \mathrm{P}-\mathrm{SRL}$ enhances the second-order rate constant of restrictocin-catalyzed cleavage. ${ }^{32} \mathrm{P}-\mathrm{SRL}$ was purified using a polyacrylamide gel that contained $8 \mathrm{M}$ urea. The gel slice was excised and eluted in $1.5 \mathrm{~mL}$ TE (10 mM Tris·HCl, $1 \mathrm{mM}$ EDTA buffer, $\mathrm{pH}$ 7.4), purified by SepPak C-18 column and dried in a Speed-Vac concentrator. Water was then added as indicated in the figure, and the resulting ${ }^{32} \mathrm{P}-\mathrm{SRL}$ was used for the cleavage experiments. (B) ${ }^{32} \mathrm{P}-\mathrm{SRL}$ diluted in $10 \mathrm{~mL}$ water binds to restrictocin with an affinity of $4 \mathrm{nM}$ as compared to 15 $\mathrm{nM}$ for dilution in $1 \mathrm{~mL}$ (Results). (C) Elution of a blank gel slice followed by the same purification steps as in (A) results in a solution that inhibits cleavage of SRL by restrictocin. From left to right, the first three bars show $15 \mu$ reaction containing no gel eluate, $1.5 \mu 1$ gel eluate and $10 \mu \mathrm{l}$ gel eluate, respectively. The last bar shows inhibition by the eluate substance precipitated by $70 \%$ ethanol, $0.3 \mathrm{M}$ Na-acetate and re-dissolved in water. The inhibitory 
substance precipitated quantitatively. (D) Linear polyacrylamide inhibits the restrictocincatalyzed SRL cleavage reaction. Conditions were as in (C).

Figure S3. Effect of RNA length on the salt dependence of restrictocin-catalyzed cleavage. The slope of the salt dependece reaches an apparant maximum at $\sim 25$ nucleotides. Reactions contained $<1 \mathrm{nM}{ }^{32} \mathrm{P}$-labeled substrates, $1 \mathrm{nM}-10 \mu \mathrm{M}$ restrictocin and $0-250 \mathrm{mM} \mathrm{KCl}$. The following substrates were used: pGpA, 11-mer RNA with the sequence UCAmGUACmGAGA ( $\mathrm{mG}=2^{\prime}$-methoxy guanosine), wild-type SRL, 37-mer SRL with the WC-stem extended by 5 base pairs, and 27-mer SRL with the 3'-end ligated either to either a 24-mer or a 48-mer ssDNA. DNA sequences were designed to avoid structure formation or base pairing with the SRL. The SRL-DNA chimeras exhibited the same cleavage rate and salt dependence as wild-type SRL.

Figure S4. Measurement of binding between the products of SRL cleavage $\left(\mathrm{P}_{1}\right.$ and $\left.\mathrm{P}_{2}\right)$ using an RNase T1 protection assay. (A) $\mathrm{P}_{2}$ and 12-CMP bind to $\mathrm{P}_{1}$ forming 6 and 12 Watson-Crick base pairs, respectively. (B) Assay flow chart and kinetic scheme. Binding of $\mathrm{P}_{2}$ to RNase T1 or to $\mathrm{P}_{1}$ should protect $\mathrm{P}_{1}$ from cleavage by the ribonuclease due to competiton and base pairing, respectively. The asterisk shows the position of the ${ }^{32} \mathrm{P}-1$ label. (C) Protection of $\mathrm{P}_{1}$ from cleavage by the RNase $\mathrm{T} 1$ in the presence of $\mathrm{P}_{2}$ (closed circles) and 12-CMP (open triangles). The data were fit to a binding isotherm $f=K_{d} /\left(K_{d}+[C]\right)$, where $f$ is the normalized $P_{1}$ cleavage rate, $C$ is concentration of $\mathrm{P}_{2}$ or $12-\mathrm{CMP}$, and $\mathrm{K}_{\mathrm{d}}$ is an apparent binding constant. Conditions: $37{ }^{\circ} \mathrm{C}, 18$ $\mathrm{nM}$ RNase T1, less than $1 \mathrm{nM}{ }^{32} \mathrm{P}$ 5'-labeled $\mathrm{P}_{1}, 10 \mathrm{mM}$ Tris· $\mathrm{HCl}$ (pH 7.4), $5 \mathrm{mM} \mathrm{KCl,} 0.05 \%$ Triton-X-100. 
Figure S5. Restrictocin preferentially cleaves guanosines within single-stranded regions of RNA. (A) Kinetic parameters $\mathrm{k}_{2}$ and $\mathrm{K}_{1 / 2}$ for cleavage of a 26-mer RNA hairpin (HP26) by restrictocin. Conditions were as in (Figure 3A), restrictocin concentrations were as indicated. HP26 has the following sequence: 5'-CCUGCGGUUCCCUCUGGAACCGCAGG. Comparison of the $\mathrm{k}_{2}$ for restrictocin-catalyzed cleavage of ssRNA, SRL G15-2'OMe and HP26, normalized by the number of guanosines.

Figure S6. Establishing the chemical form of the scissile phosphate in the product of SRL cleavage by restrictocin. (A) Building internally ${ }^{32} \mathrm{P}$-labeled SRL (SRL ${ }^{\mathrm{P}}$ ) via two-piece ligation. The internally radiolabeled $\mathrm{SRL}^{\mathrm{P}}$ reacts with restrictocin with the same rate as $5{ }^{\prime}-{ }^{32} \mathrm{P}-\mathrm{SRL}$. (B) Following cleavage with restrictocin, $\mathrm{SRL}^{\mathrm{P}}$ forms $\mathrm{P}_{1}$ containing ${ }^{32} \mathrm{P}$-label at the 3 '-end that resists alkaline phosphatase treatment, consistent with the presence of 2', 3'-cyclic phosphate. Sequences of the 5'- and 3' halves of the $\operatorname{SRL}\left(\mathrm{P}_{1}\right.$ and $\left.\mathrm{P}_{2}\right)$ and of the DNA splint are provided in Table 1. AP designates alkaline phosphatase; star designates ${ }^{32} \mathrm{P}$ phosphate.

Figure S7. Restrictocin-mediated SRL cleavage results in formation of a 2',3'-cyclic phosphate. Treatment of the reaction products with alkaline phosphatase does not release the ${ }^{32} \mathrm{P}$ label, suggesting that $\mathrm{P}_{1}$ contains a 2',3'-cyclic phosphate, which is resistant to alkaline phosphatase. Prolonged incubation of $\mathrm{P}_{1}$ in the reaction media leads to the opening of the cyclic phosphate to form $2^{\prime}$ or $3{ }^{\prime}{ }^{32} \mathrm{P}$ phosphate monoesters that undergo hydrolysis by alkaline phosphatase and release the inorganic phosphate into solution. 
Figure S8. The pH-rate profile for restrictocin-catalyzed cleavage of a single-stranded RNA 27mer (Table 1) under $\mathrm{k}_{2}$ conditions. Reactions were conducted at $37^{\circ} \mathrm{C}$ in $10 \mathrm{mM}$ Tris $\cdot \mathrm{HCl}$ buffer and contained $<1 \mathrm{nM}^{32} \mathrm{P}$-ssRNA, $1 \mu \mathrm{M}$ restrictocin and $0.05 \%$ Triton-X-100.

Figure S9. Stimulation of RNase T1 - catalyzed cleavage of ssRNA 27-mer by $\mathrm{KCl}$ (A), spermine (B) and restrictocin (C) under sub-saturating conditions. Reactions were conducted at $37{ }^{\circ} \mathrm{C}$ in $10 \mathrm{mM}$ Tris $\cdot \mathrm{HCl}$ buffer (pH 7.4) and contained $<1 \mathrm{nM}{ }^{32} \mathrm{P}-5$ '-ssRNA, $5 \mathrm{nM}$ RNase T1 (A, B) or $28.6 \mathrm{nM}$ RNase $\mathrm{T} 1$ (C) and $0.05 \%$ Triton-X-100. 
A

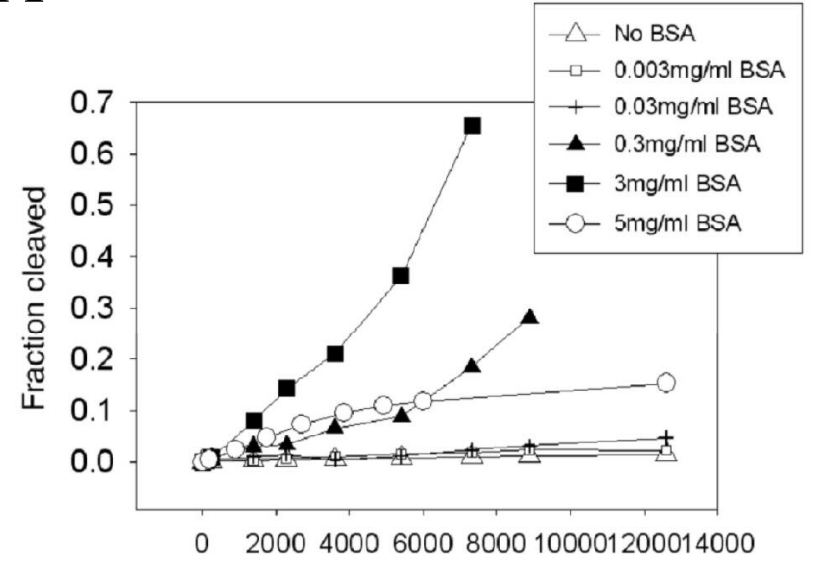

time (s)
B

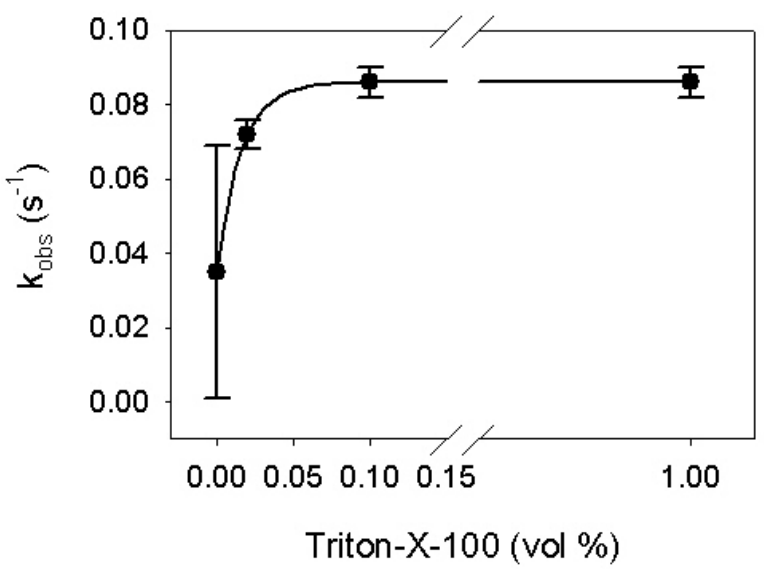

\section{Figure S1}


A

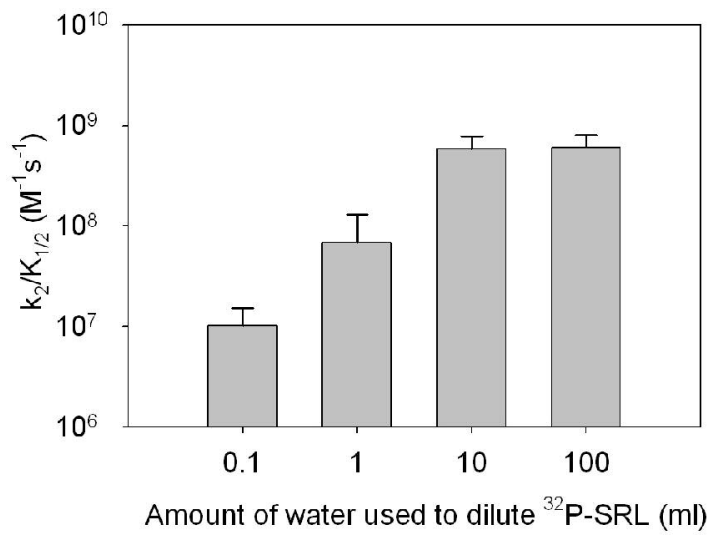

C

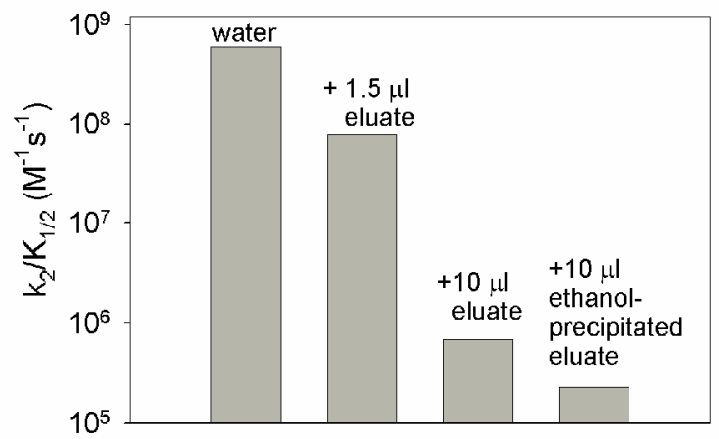

B

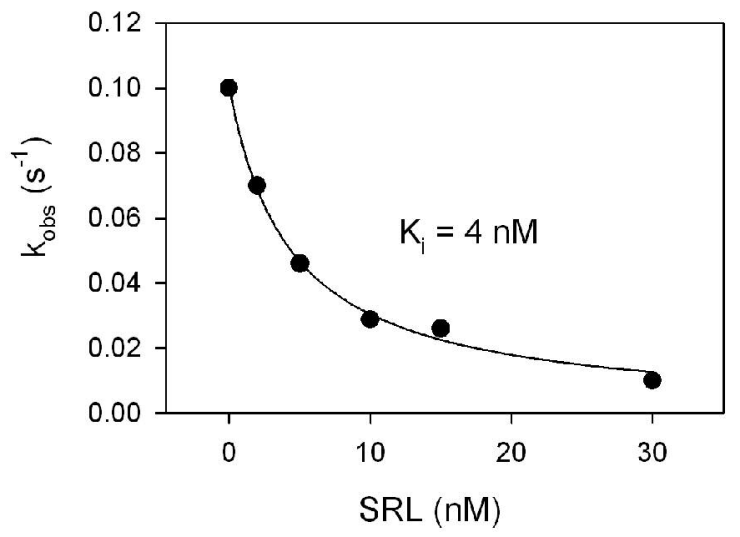

D

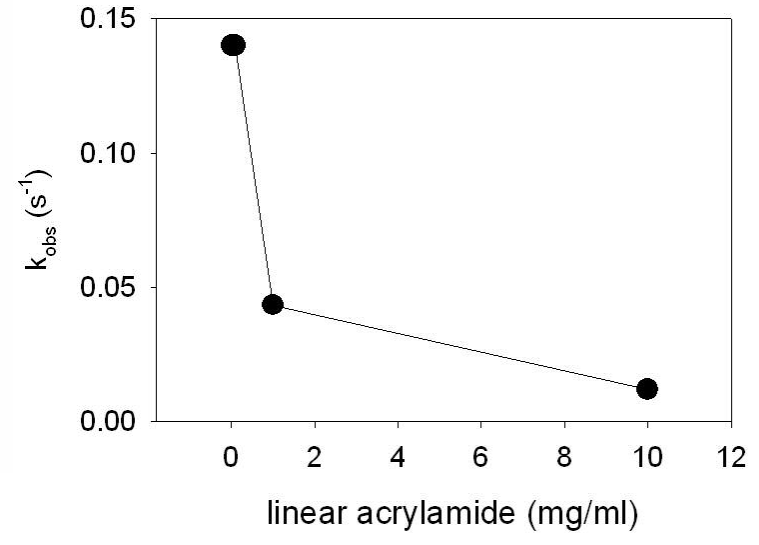

Figure S2 


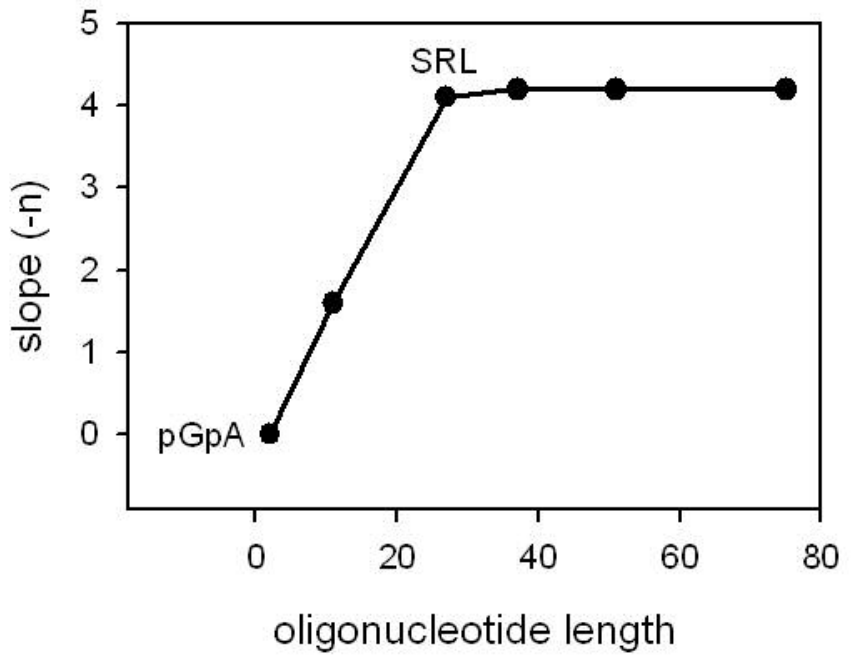

Figure S3 
A
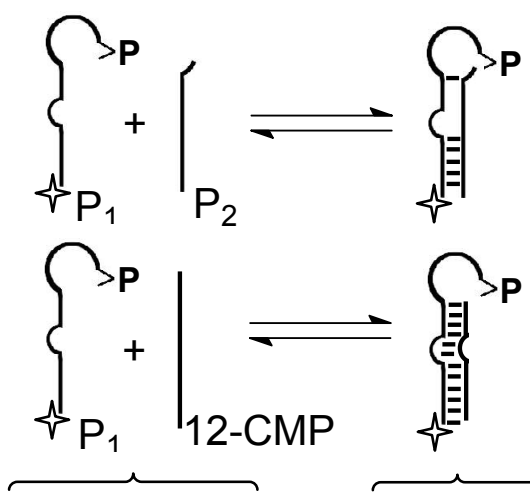

$\underbrace{\text { react with } \mathrm{T} 1} \quad \underbrace{\text { resist } \mathrm{T} 1}$

B

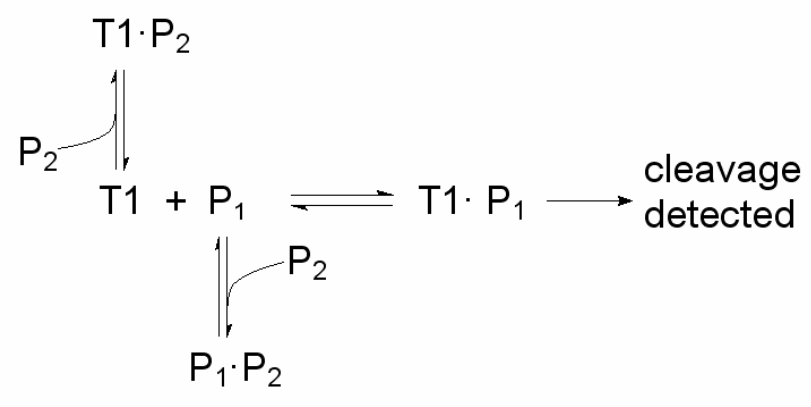

C

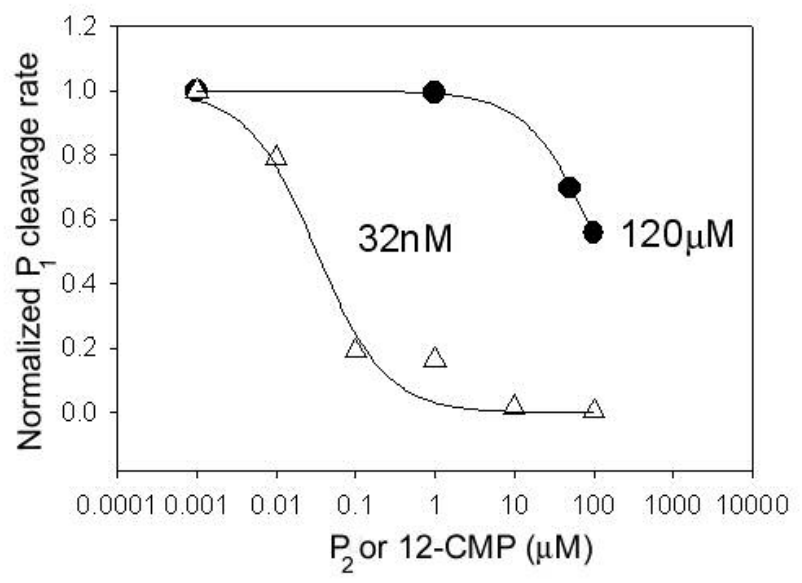


Figure S4

A

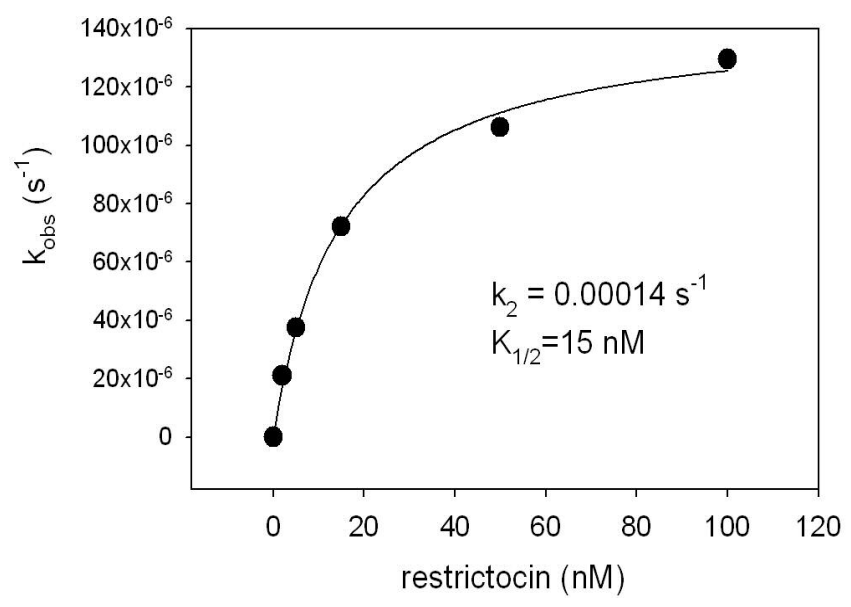

B

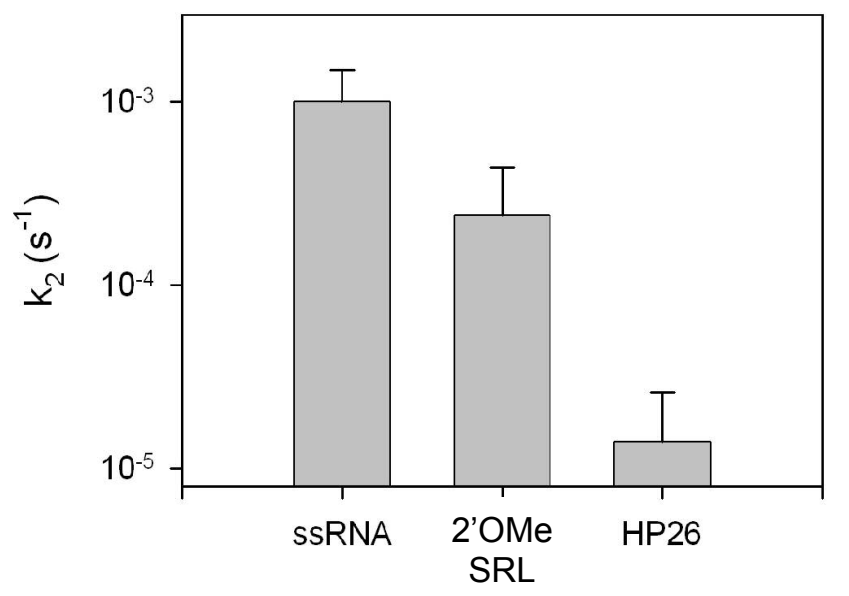


A
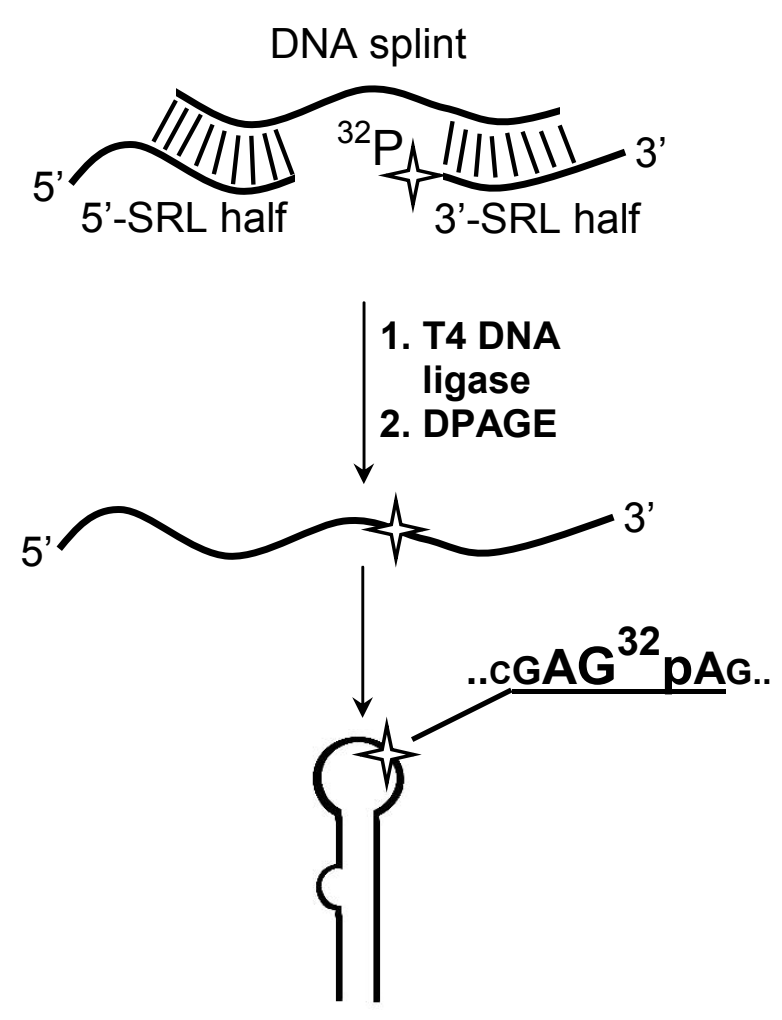

full-length $S R L$ with ${ }^{32} P$ at the cleavage site $\left(\mathrm{SRL}^{\mathrm{P}}\right)$
B
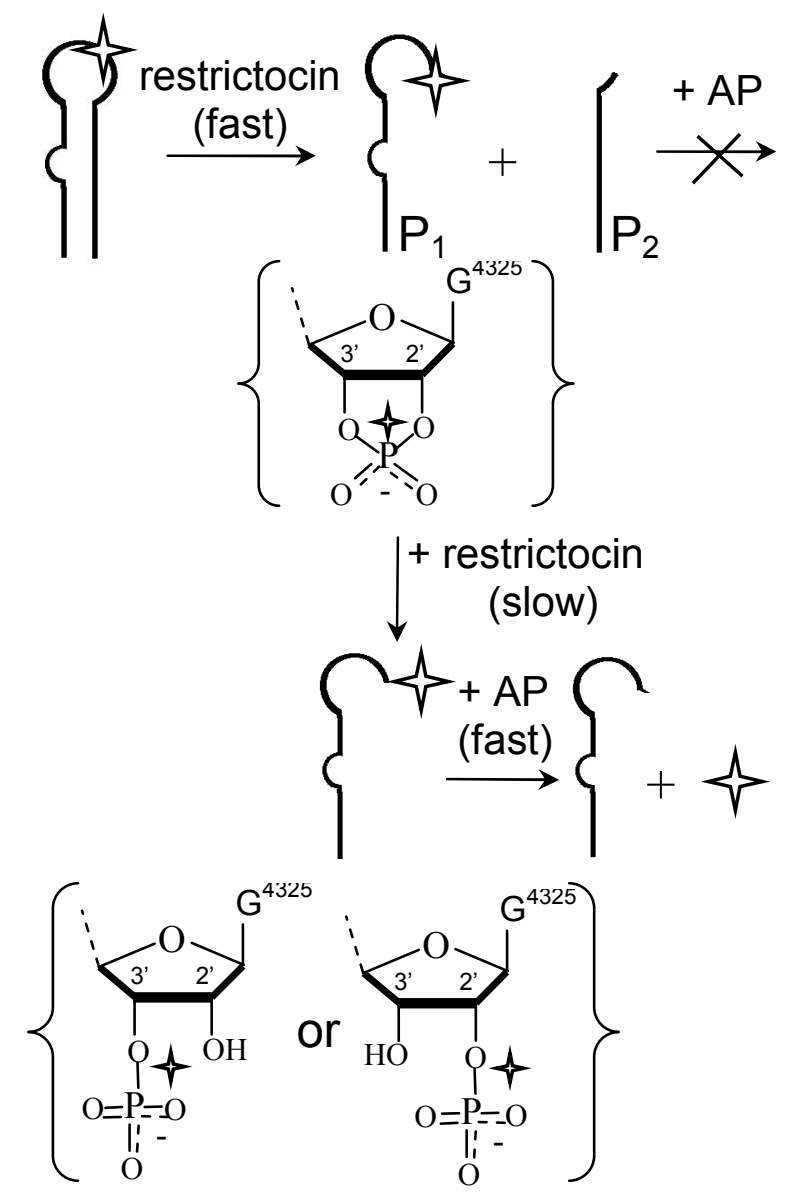


\section{Figure S6}

\begin{tabular}{|c|c|c|c|c|c|c|}
\hline \multicolumn{6}{|c|}{ Cleavage of $\mathrm{SRL}^{\mathrm{P}}$ with restrictocin } & \multirow{2}{*}{$\begin{array}{l}\text { Control } \\
5^{3}{ }^{32} \mathbf{P}-\mathrm{S}\end{array}$} \\
\hline Step $1 \longdiv { \text { min: } 0 }$ & 0.1 & 1 & 2 & 3 & 5 & \\
\hline
\end{tabular}

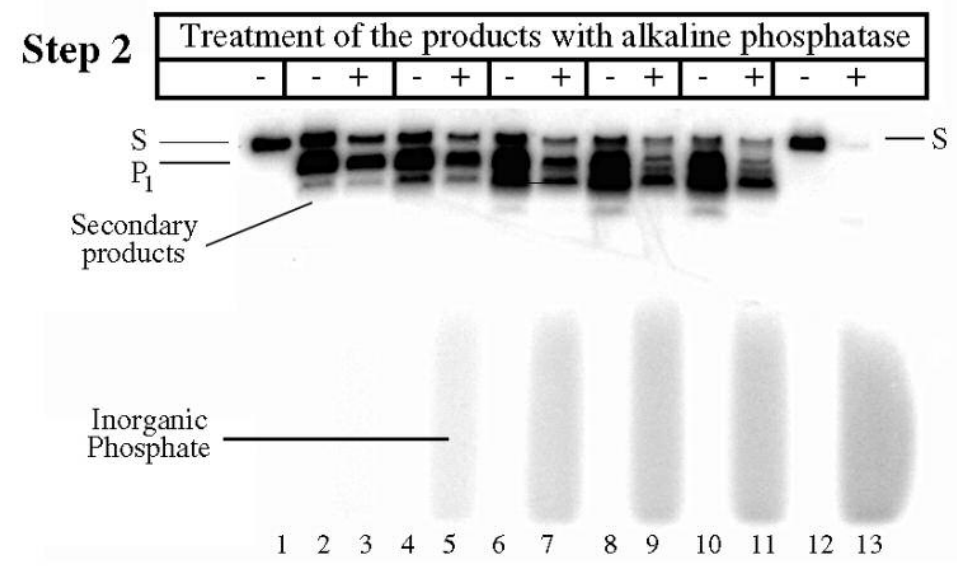


Figure S7

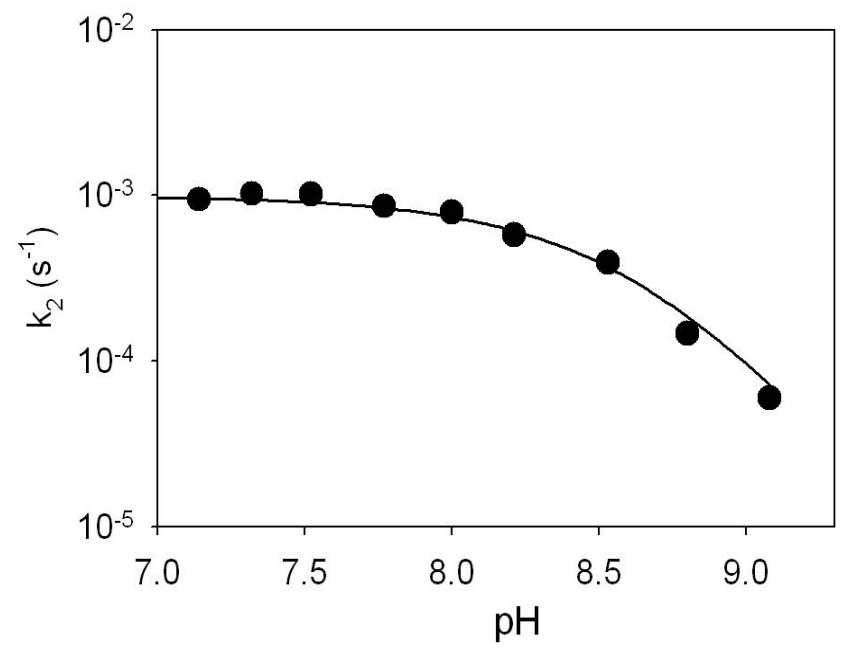




\section{Figure S8}

A

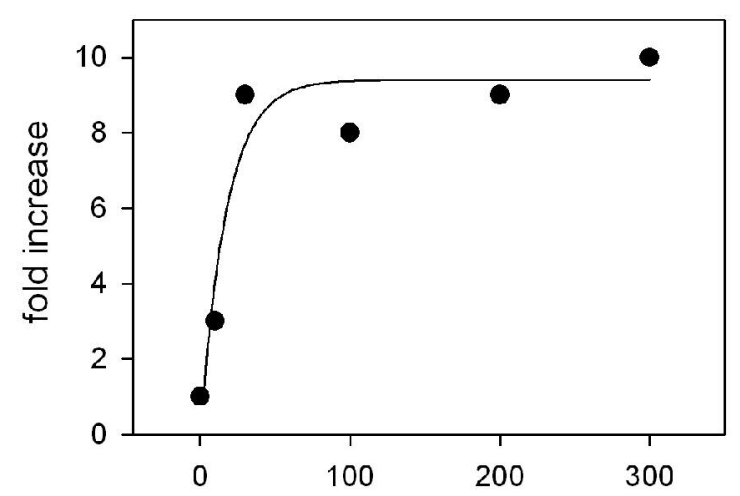

C

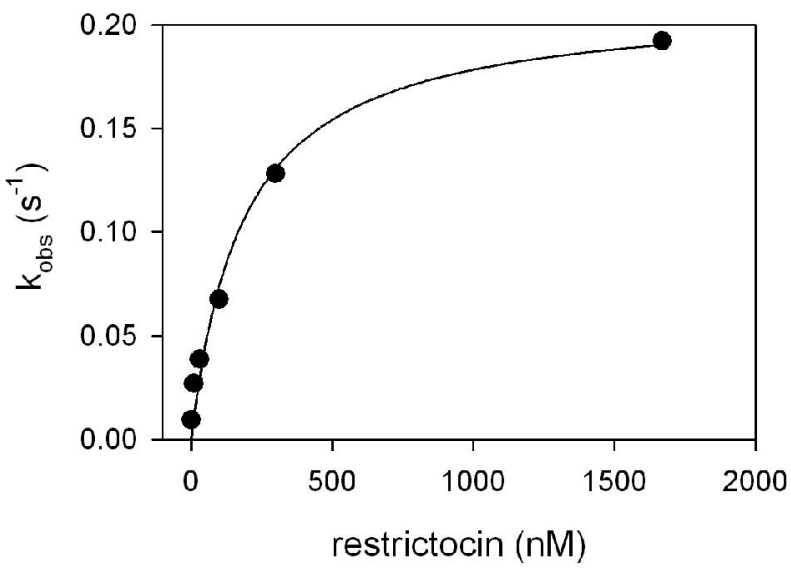

\section{B}

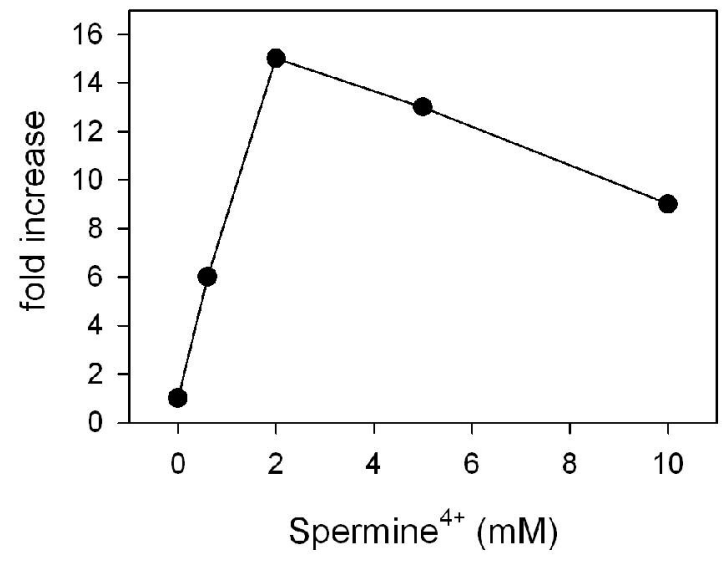

Figure S9 